\title{
Estimation of phytomass for ungrazed crested wheatgrass plants using allometric equations
}

\author{
PATRICIA S. JOHNSON, CRAIG L. JOHNSON, AND NEIL E. WEST
}

\section{Abstract}

The allometric relationship between plant volume and phytomass of crested wheatgrass was studied for the 1981, 1983, and 1984 growing seasons in west-central Utah. Basal diameters, canopy diameters, and standing plant heights were measured for individual plants. Three models of volume (basal elliptical cylinder, canopy elliptical cylinder, and elliptical cone section) were tested as predictors of plant phytomass using nonlinear regression. Elliptical cone section produced the highest $R^{2}$ and lowest SEE, but requires measurement of canopy diameters which may be subject to excessive measurement error. Basal elliptical cylinder produced $R^{2}$ and SEE values nearly comparable to those of the elliptical cone section; moreover, this model does not require measurement of canopy diameters, making it the practical choice. Nonlinear regressions for plants by size class (small, medium and large) were produced using 1983 data. Predictive ability of size class-specific equations was compared to that of the equation for all size classes combined. When phytomass of only small or medium size class plants was predicted, the SEE of size class-specific equations was slightly lower than the SEE of the equation for all size classes combined. When phytomass of plants from all size classes was predicted, however, the equation for all size classes combined produced the lowest combined SEE for new data (i.e., dats not used to generate the equation). There were substantial year-to-year differences between equations, which indicates the necessity of producing new equations each year.

Key Words: Agropyron desertorum, volume-weight relationships, nonlinear regression, biomass prediction

There is considerable interest in using nonlinear models to predict plant biomass (phytomass) because these models generally fit biological data as well as, if not better than, linear models (Payandeh 1983). Allometric equations, which are nonlinear models of the form $y=a X^{b}$ (Causton and Venus 1981), have been used very successfully to describe relationships between various plant measurements and phytomass. There is an enormous literature reporting the use of allometric equations to relate the phytomass (total, foliage, wood, etc.) of many tree and shrub species to such variables as stem or bole diameter, crown area, and plant height (e.g., Ohmann et al. 1976, Tritton and Hornbeck 1982, Smith and Brand 1983). The generally high $R^{2}$ values indicate a good fit, and many equations predict phytomass well (e.g., Crow 1978, Payandeh 1981, Tritton and Hornbeck 1982).

Allometric equations have also been fitted to grass and forb data (e.g., Ohmann et al. 1981, Smith and Brand 1983), but are less common than those for trees and shrubs. The $\boldsymbol{R}^{2}$ values are generally low, which may be the result of inappropriate predictor variables, regression model, or both. Percent cover is the most common independent variable used in phytomass prediction equations for grasses and forbs. Large coefficients of variation are associated with low vegetation cover estimates (less than $40 \%$ cover) (Hatton

\footnotetext{
Authors are assistant professor and research assistant, Department of Animal and Range Sciences, South Dakota State University, Brookings 57007; and professor, Range Science Department, Utah State University, Logan 84322 . At the time of the research, the 2 senior authors were research associate and research technician, Range Science Department, Utah State University.

Utah Agricultural Experiment Station Journal Paper No. 3544

The authors acknowledge the assistance of John Madany and Eric Johnson for data collection and Charles Warner for illustrations.

Manuscript accepted 10 May 1988.
}

et al. 1986), which are common for grasses and forbs. In addition, foliage density and height, and thus phytomass, can be quite variable for any given cover value, introducing still more variation and contributing to a poor fit. An alternative predictor variable is canopy volume, which has not been widely used but which has a strong theoretical relationship to phytomass (Tausch 1980). Canopy volume has shown promise for several grasses and a forb, with coefficients of determination for grasses exceeding 0.80 for both linear and allometric regression equations (Tausch 1980).

Phytomass estimation of grasses and forbs is an important problem in range research and is crucial in evaluation of production and utilization. Considerable effort has gone into examination of relationships between measurable plant attributes and phytomass, and there is a great need for identification of those relationships that will allow accurate prediction of phytomass. The objectives of this study were (1) to describe the relationship between crown volume and phytomass for a single caespitose grass species, crested wheatgrass (Agropyron desertorum (Fisch. ex Link)Schult.) using nonlinear regression analysis, (2) to evaluate the accuracy of these equations in predicting phytomass, and (3) to determine whether these allometric equations varied over time.

\section{Methods}

The study was conducted in Tintic Valley, approximately $8 \mathrm{~km}$ southwest of Eureka, Utah, on a research area maintained cooperatively by Utah State University and the Bureau of Land Management (U.S. Department of Interior). The area has an elevation of approximately $1,830 \mathrm{~m}$ and an average precipitation of $320 \mathrm{~mm}$, the majority of which falls in winter and spring (Cook 1966). Twenty-four improved pastures ( 28 ha each) were established on the area in the late 1940's and early 1950's on land previously dominated by sagebrush (Artemisia tridentata Nutt. spp. tridentata Beetle) and juniper (Juniperus osteosperma [Torr.] Little). The 9 improved pastures utilized in this study had been seeded to crested wheatgrass either in monoculture or in combination with 1 or more other grass species following removal of the woody species.

Crested wheatgrass plants were protected from livestock grazing and sampled during the 1981, 1983, and 1984 growing seasons. Since genetically distinct individuals are difficult to distinguish in caespitose grasses, a plant was defined as a clump of continuous grass cover that is spatially distinct from its neighbors. Plants selected at each sampling date were chosen to represent the range of plant sizes (based on basal area) in the pasture sampled. Standing plant height and 2 or more diameters were measured on each plant. Diameter measurements excluded dead areas of the plant crown greater than $1 \mathrm{~cm}$ in diameter. The plants were then clipped to the crown and any dead material from previous growing seasons was removed. Each plant was placed in a paper bag, oven dried at $70^{\circ} \mathrm{C}$, and weighed. Data collection methods varied between years, especially as regards diameter measurements, pastures sampled, and sampling dates. The following sections provide additional information on collection methods.

\section{Data}

Approximately 35 plants were collected on each of 5 dates in pasture 17 (13 May to 9 June at about 1-week intervals), on each of 


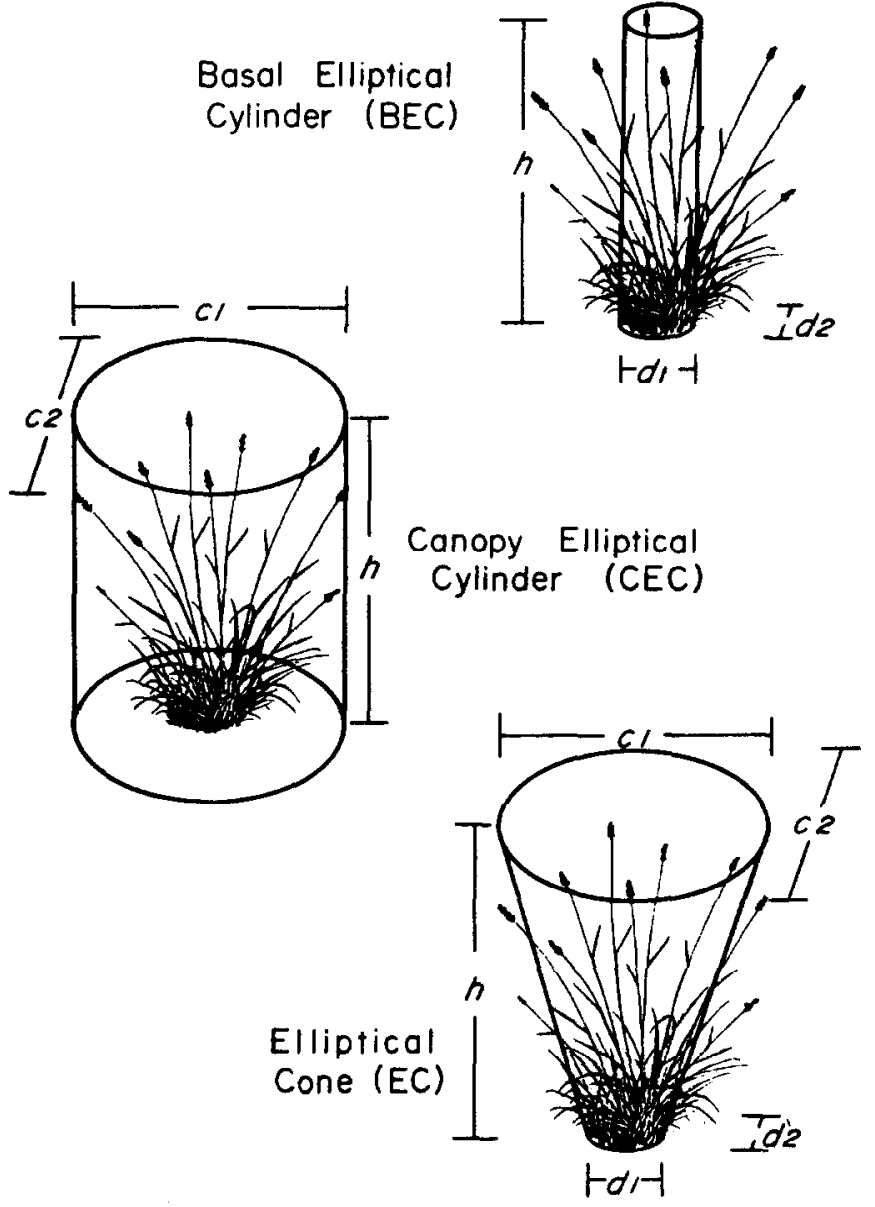

Fig. 1. Diagrammatic representation of a crested wheatgrass plant and three models for describing its volume.

9 dates in pasture 19 (6 May to $10 \mathrm{July}$ at about 1 -week intervals) and on each of 5 dates in pasture 8 (17 June to $15 \mathrm{July}$ at about 1-week intervals). Total sample size was 669. Two basal (crown) diameters for each plant were measured (the greatest and the greatest perpendicular to the first) and averaged, and the average basal diameter was recorded in the field.

\section{Data}

Approximately 15 plants were collected from each of 4 pastures $(2,8,18$, and 22) on each of 4 dates: 26 May, 31 May, $8 \mathrm{June}$, and 23 June. An additional 15 plants were collected from each of 2 pastures (14 and 19) on all but the first sampling date. Total sample size was 324. Diameter measurements recorded in the field for each plant included:

$$
d_{1}=\text { longest basal diameter }
$$

$d_{2}=$ longest basal diameter perpendicular to $d_{1}$

$c_{1}=$ longest canopy diameter

$c_{2}=$ longest canopy diameter perpendicular to $c_{1}$

\section{Date}

A total of 43 plants were collected on 13 May from pastures 8, 14,18 , and 19 and a total of 50 plants were collected on $28 \mathrm{June}$ from pastures $9,10,17,18$, and 19. Total sample size was 93 . Diameter measurements were determined as in 1983.

\section{Analyses}

Three models (Fig. 1) were used to describe the volume occupied by the aboveground portion of crested wheatgrass plants: (1) basal elliptical cylinder (BEC) calculated using basal diameters and plant height, (2) canopy elliptical cylinder (CEC) calculated using canopy diameters and plant height, and (3) elliptical cone section (EC) calculated using plant height and both canopyand basal diameters. Equations for calculating these volumes are:

$$
\begin{aligned}
\mathrm{BEC} & =\frac{\pi \mathrm{d}_{1} \mathrm{~d}_{2} \mathrm{~h}}{4} \\
\mathrm{CEC} & =\frac{\pi \mathrm{c}_{1} \mathrm{c}_{2} \mathrm{~h}}{4} \\
\mathrm{EC} & =\frac{\pi \mathrm{h}}{6}\left(\frac{\mathrm{d}_{1} \mathrm{~d}_{2}}{4} \frac{\mathrm{d}_{2} \mathrm{c}_{1}}{4}-\frac{\mathrm{c}_{1} \mathrm{c}_{2}}{2} \frac{\mathrm{d}_{1} \mathrm{~d}_{2}}{2}\right)
\end{aligned}
$$

where: $d_{1}=$ longest basal diameter $\left(d_{1}=d_{2}\right.$ for 1981 data $)$

$d_{2}=$ longest basal diameter perpendicular to $d_{1}$

$c_{1}=$ longest canopy diameter

$c_{2}=$ longest canopy diameter perpendicular to $c_{1}$

$\mathrm{h}=$ standing plant height

Allometric equations of the form:

$$
\begin{aligned}
& y=a+b V^{e} \\
& \text { where } y=\text { phytomass }(\mathrm{B}) \\
& \mathrm{V}=\text { canopy volume }\left(\mathrm{cm}^{3}\right) \text { defined as BEC, CEC or EC, above and }
\end{aligned}
$$$$
a, b \text { and } c=\text { nonlinear regression coefficients, }
$$

were fitted to data using a Simplex algorithm (Caceci and Cacheris 1984). Goodness of fit was measured by $R^{2}$ and standard error of the estimate (SEE) was used to express precision of estimation. Residuals for these analyses were determined to be approximately normally distributed.

The 9 plant size classes of Norton and Johnson $(1981,1986)$ were reduced to three: (1) small (basal area $\left.<80 \mathrm{~cm}^{2}\right)$, (2) medium $(80$ $\mathrm{cm}^{2} \leq$ basal area $<180 \mathrm{~cm}^{2}$ ), and (3) large (basal area $\geq 180 \mathrm{~cm}^{2}$ ). Data from 1983 were divided according to these classes for analysis by size.

The data sets for the 3 years as well as data for the 3 size classes in

\begin{tabular}{|c|c|c|c|c|c|c|}
\hline \multirow[b]{2}{*}{ Year } & \multirow[b]{2}{*}{ Volume 1} & \multicolumn{4}{|c|}{ Nonlinear regression coefficients ${ }^{2}$} & \multirow[b]{2}{*}{ SEE } \\
\hline & & a & b & c & $R^{2}$ & \\
\hline 1983 & $\begin{array}{r}\text { BEC } \\
\text { CEC } \\
\text { EC }\end{array}$ & $\begin{array}{l}2.547147 \\
0.113934 \\
4.429602\end{array}$ & $\begin{array}{l}0.001011 \\
0.000028 \\
0.000007\end{array}$ & $\begin{array}{l}1.120109 \\
1.299936 \\
1.485287\end{array}$ & $\begin{array}{l}0.8463 \\
0.7982 \\
0.8817\end{array}$ & $\begin{array}{l}7.9629 \\
9.1247 \\
6.9871\end{array}$ \\
\hline 1984 & $\begin{array}{r}\text { BEC } \\
\text { CEC } \\
\text { EC }\end{array}$ & $\begin{array}{r}0.080242 \\
-0.468961 \\
-0.269877\end{array}$ & $\begin{array}{l}0.013790 \\
0.006120 \\
0.006946\end{array}$ & $\begin{array}{l}0.777349 \\
0.797446 \\
0.812984\end{array}$ & $\begin{array}{l}0.7957 \\
0.7664 \\
0.7963\end{array}$ & $\begin{array}{l}4.7705 \\
5.1016 \\
4.7644\end{array}$ \\
\hline
\end{tabular}
1983 were each randomly divided into 2 groups. The first (the fitted data) consisted of approximately $70 \%$ of the data from an original data set and were used to generate a nonlinear regression equation. The remaining $30 \%$ (the test data) were used to validate the regression equation (Snee 1977). SEE was calculated separately for the

Table 1. Comparison of 3 volume models for crested wheatgrass plants for 1983 and 1984 using nonlinear regresdon analysis.

IVolume models are basal elliptical cylinder (BEC), canopy elliptical cylinder (CEC) and elliptical cone section (EC).

${ }_{2 N o n l i n e a r}$ regression model is $y=a+b V^{c}$ where $y=$ phytomass, and $V=$ plant volume (calculated as BEC, CEC, or EC). 
Table 2. Comparison of nonlinear rezreacion equations for small, medium, large and all size classes of crested wheatgrass plants collected in 1983, uaing data to which equations were fitted (70\% of each data set) and teat data (remuining $30 \%$ of each data set).

\begin{tabular}{|c|c|c|c|c|c|c|c|c|c|c|}
\hline \multirow{2}{*}{$\begin{array}{l}\text { Size } \\
\text { Class }\end{array}$} & \multicolumn{3}{|c|}{$\begin{array}{c}\text { Nonlinear } \\
\text { Regression coefficients } 1\end{array}$} & \multicolumn{4}{|c|}{$\begin{array}{c}\text { Fitted } \\
\text { Data statistics }\end{array}$} & \multicolumn{3}{|c|}{$\begin{array}{c}\text { Test } \\
\text { Data statistics }\end{array}$} \\
\hline & $\mathbf{a}$ & b & c & $\mathbf{n}$ & $R^{2}$ & $\mathrm{SEE}_{\boldsymbol{w}}$ & SEE $_{\text {all }}$ & $\mathbf{n}$ & $S E E_{\boldsymbol{c c}}$ & SEE $_{\text {all }}$ \\
\hline $\begin{array}{l}\mathbf{S} \\
\mathbf{M} \\
\mathbf{L}\end{array}$ & $\begin{array}{l}1.3780 \\
4.8534 \\
2.6373\end{array}$ & $\begin{array}{l}0.000031 \\
0.000005 \\
0.000293\end{array}$ & $\begin{array}{l}1.6301 \\
1.7478 \\
1.2344\end{array}$ & $\begin{array}{r}110 \\
72 \\
46\end{array}$ & $\begin{array}{l}0.795 \\
0.721 \\
0.873\end{array}$ & $\begin{array}{r}1.964 \\
5.768 \\
13.982\end{array}$ & $\begin{array}{r}2.723 \\
7.463 \\
14.465\end{array}$ & $\begin{array}{l}50 \\
30 \\
14\end{array}$ & $\begin{array}{r}2.584 \\
6.183 \\
21.478\end{array}$ & $\begin{array}{r}2.725 \\
6.220 \\
19.912\end{array}$ \\
\hline ALL & 2.5298 & 0.000797 & 1.4111 & 228 & 0.873 & 7.149 & 7.843 & 94 & 8.872 & 8.207 \\
\hline
\end{tabular}

INonlinear regression model is $y=a+b V^{c}$ where $y=$ phytomass and $V=$ plant volume calculated as $B E C$.

fitted data and the text data for all years; SEE was also calculated for each size class for the 1983 data using size class-specific equations $\left(S E E_{w c}\right)$ and for the equation in which all size classes were combined (SEE all). In order to determine SEE for an entire fitted or test data set (all size classes combined) when size class-specific equations were used, the equation to calculate SEE was expanded:

$$
\operatorname{SEE}=\left(\frac{\Sigma\left(y_{i}-\hat{y}_{i}\right)^{2}+\Sigma\left(y_{j}-\hat{y}_{j}\right)^{2}+\Sigma\left(y_{k}-\hat{y}_{k}\right)^{2}}{n_{i}+n_{j}+n_{k}-6}\right) 1 / 2
$$

where $y \hat{\mathbf{r}}=$ the observed phytomass and $\hat{\mathbf{y}}_{\mathbf{r}}=\hat{\mathbf{a}}+\hat{\mathbf{b}} \mathbf{\hat { c }} \mathbf{r}$
for:

the ith small plant when $r=i$,

the jth medium plant when $r=j$, and

the kth large plant when $r=k$, where:

$\hat{a}, \hat{b}$ and $\hat{c}=$ nonlinear regression coefficients of the size class-specific equations, and

$n_{j}, n_{j}$, and $n_{k}=$ sample size for small, medium and large size classes, respectively.

Residuals for these analyses were determined to be approximately normally distributed.

\section{Results and Discussion}

The fit of each model of crested wheatgrass plant volume (basal elliptical cylinder, canopy elliptical cylinder and elliptical cone) was tested using only the 1983 and 1984 data because canopy diameters, and thus CEC and EC, were unavailable for 1981. The results of nonlinear regression analysis (Table 1) indicated that the elliptical cone model provided the best fit, canopy elliptical cylinder the poorest, and basal elliptical cylinder was intermediate. The shape of a crested wheatgrass plant is more conical than cylindrical (Fig. 1), so it is not unlikely that the relationship between EC and phytomass would produce the best results. The improvement in SEE and $R^{2}$ when equations in which EC rather than BEC was the independent variable is not as great as might be ixpected. This is likely due to the fact that calculation of conical volume requires canopy diameters, which are subject to more measurement error than basal diameters. Canopy boundaries are seldom well defined, and windy conditions increase the subjectivity of measurement. Basal diameter measurements, on the other hand, are much easier to obtain and the results are more reliable, as indicated by the higher $R^{2}$ and lower SEE for BEC compared to those for CEC.

The error associated with estimating canopy diameters can reduce the advantage gained by calculating plant volume using the more realistic elliptical cone equation. The expense of measuring canopy diameters in addition to basal diameters makes it apparent that, of the models considered, the basal elliptical cylinder provides a good compromise of realism, reliability and expense. Thus we have chosen to use volume calculated as BEC for the data presented in this paper.

Results of nonlinear regression analysis for plants collected in 1983 and separated into 3 size classes are presented in Table 2 . As

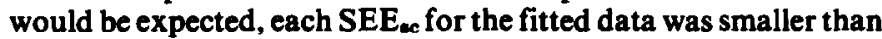
$S E E_{\boldsymbol{~}}$ for the test data. A comparison of the size class-specific equations with the equation generated for all size classes in terms of their ability to predict phytomass for each size class (SEE ac $_{\text {versus }}$ SEE $_{\text {all }}$ ) produced mixed results (Table 2). Phytomass was best predicted using size class-specific equations rather than the equation for all size classes combined in all cases except for large test plants. The difference between $S E_{\alpha c}$ and $S E_{a l l}$ was usually relatively small, which indicates only a small advantage in producing separate equations for each size class.

Another comparison of the precision of estimation of size classspecific equations versus the equation for all size classes combined was made using plants of the entire (all size classes combined) fitted and test data sets (Table 2). Again, there were only small differences between $S E E_{a c}$ and $S E E_{\text {all }}$ for both the fitted and test data. For the fitted data, $S E E_{\text {all }}$ exceeds $S E E_{\alpha c}$, with the reverse being the case for the test data. The small differences between $\mathrm{SEE}_{\infty}$

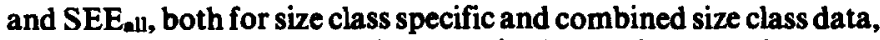
indicate there is no great advantage in developing equations specific to plant size, especially when phytomass must be predicted for plants from a wide range of size classes. If, however, phytomass of only small and medium sized plants is to be predicted, the greater precision of prediction may be sufficient justification for collection of sufficient data to generate 2 separate nonlinear regression curves.

Ideally a nonlinear equation relating plant volume to phytomass for 1 year would be valid for all years. However, this does not appear to be the case for crested wheatgrass. The coefficient $c$ (the

Table 3. Comparison of nonlinear regresaion equations for 3 years using $R^{2}$ and SEE for data to which equations were fitted (70\% of each data set) and SEE for test data (remaining $30 \%$ of each data set).

\begin{tabular}{|c|c|c|c|c|c|c|c|c|}
\hline \multirow[b]{2}{*}{ Year } & \multicolumn{3}{|c|}{$\begin{array}{c}\text { Nonlinear } \\
\text { Regression coefficients' }\end{array}$} & \multicolumn{3}{|c|}{$\begin{array}{c}\text { Fitted } \\
\text { Data statistics }\end{array}$} & \multicolumn{2}{|c|}{$\begin{array}{c}\text { Test } \\
\text { Data statistics }\end{array}$} \\
\hline & a & b & c & $\mathbf{n}$ & $R^{2}$ & SEE & n & SEE \\
\hline $\begin{array}{l}1981 \\
1983 \\
1984\end{array}$ & $\begin{array}{r}-0.749803 \\
2.529759 \\
0.145643\end{array}$ & $\begin{array}{l}0.302264 \\
0.000797 \\
0.015307\end{array}$ & $\begin{array}{l}0.337041 \\
1.141111 \\
0.759322\end{array}$ & $\begin{array}{r}460 \\
228 \\
65\end{array}$ & $\begin{array}{l}0.6790 \\
0.8734 \\
0.8253\end{array}$ & $\begin{array}{l}1.5978 \\
7.8425 \\
4.2548\end{array}$ & $\begin{array}{r}209 \\
96 \\
28\end{array}$ & $\begin{array}{l}1.6146 \\
8.2074 \\
6.2266\end{array}$ \\
\hline
\end{tabular}

'Nonlinear regression model is $y=a+b V^{c}$ where $y=$ phytomass and $V=$ plant volume calculated as BEC. 


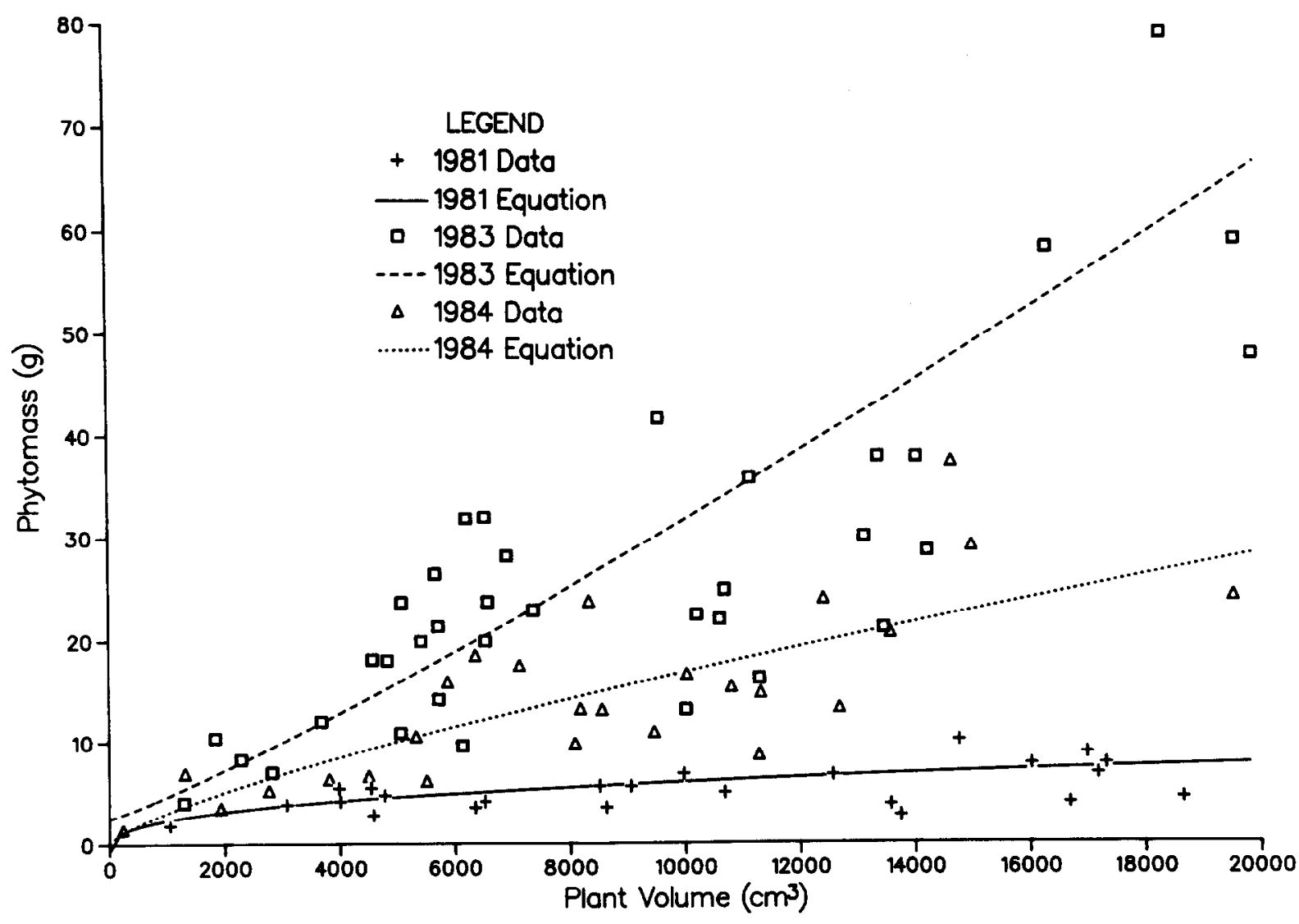

Fig. 2. Plots of random subsets of 1981, 1983, and 1984 plant volume (basal elliptical cylinder) and phytomass data, and the curves developed for those data using allometric equations.

power of the volume) ranged from 0.337041 to 1.14111 over the 3 years (Table 3). These functions were plotted over a range of canopy volumes typical for plants found at the study site (Fig. 2). Obviously the predicted phytomass for any given canopy volume changes markedly with a change in equations, and an equation fitted to data from 1 year will not accurately predict phytomass for a different year. This may be due in part to the fact that the aboveground structure of grasses is reconstructed every growing season and is subject to environmental perturbations which may affect the volume-to-weight relationship. Equations developed for shrubs and trees are probably more stable, due to the presence of a perennating structure which more regularly defines plant volume.

For the 3 years, $R^{2}$ ranged from 0.6790 in 1981 to 0.8734 in 1983 (Table 3). The low $R^{2}$ in 1981 is at least partially due to the use of average basal diameter in calculating plant volume. Since $d_{1}=d_{2}$, plant volume was calculated as a circular cylinder (a special case of an elliptical cylinder), which is often an inappropriate model of crested wheatgrass plant volume. The improvement in $R^{2}$ for equations using 1983 and 1984 data reflects the use of actual diameter measurements and the use of an elliptical cylinder (rather than circular) to describe volume.

\section{Conclusions}

Theoretically, a cone may be the most realistic model of the volume occupied by a crested wheatgrass plant; however, our results indicate that an elliptical cylinder calculated using plant basal diameters may be a more practical choice. Errors associated with measuring canopy diameter and the additional expense of these measurements make the potentially more accurate cone model less desirable. Production of nonlinear regression equations for each plant size class appears unnecessary when the phytomass of plants of a wide range of size classes is to be estimated. It may, however, be beneficial if the goal is to predict phytomass for only small and medium-sized plants. Extreme annual variation in the coefficient estimating the power of the allometric equation for crested wheatgrass indicates that the relationship between volume and weight was extremely variable. Thus, allometric equations for grass species should be generated yearly.

\section{Literature Cited}

Caceci, M.S., and W.P. Cacheris. 1984. Fitting curves to data. The Simplex algorithm is the answer. Byte (May), 340-362.

Causton, D.R., and J.C. Venus. 1981. The biometry of plant growth. Edward Arnold Ltd., London.

Cook, C.W. 1966. Development and use of foothill ranges in Utah. Utah Agr. Exp. Sta. Bull. 461.

Crow, T.R. 1978. Common regressions to estimate tree biomass in tropical stands. Forest. Sci. 24:110-114.

Hatton, T.J., N.E. West, and P.S. Johnson. 1986. Relationships of the error associated with ocular estimation and actual total cover. J. Range Manage. 39:91-92.

Norton, B.E., and P.S. Johnson. 1981. Pattern of defoliation by cattle grazing crested wheatgrass pastures. Proc XIV Internat. Grassl. Congr. 462-464.

Norton, B.E., and P.S. Johnson. 1986. Impact of grazing on crested wheatgrass in relation to plant size, p. 275-279. In: K.L. Johnson (ed), Crested wheatgrass: its values, problems and myths; Symp. proc., Utah State Univ., Logan, Utah.

Ohmann, L.F., D.F. Grizal, and R.B. Brander. 1976. Biomass estimation for 5 shrubs from northeastern Minnesota. USDA Forest Serv. Res. Pap. NC-133.

Ohmann, L.F., D.F. Griģal, and L.L. Rogers. 1981. Estimating plant biomass for undergrowth species of northeastern Minnesota forest communities. USDA Forest Serv. Gen. Tech. Rep. NC-61. 
Payandeh, B. 1981. Choosing regression models for biomass prediction equations. Forest. Chron. 57:229-232.

Payandeh, B. 1983. Some applications of nonlinear regression models in forestry research. Forest. Chron. 59:244-248.

Smith, W.B., and G.J. Brand. 1983. Allometric biomass equations for 98 species of herbs, shrubs, and small trees. USDA Forest. Serv. Res. Note NC-299.
Snee, R.D. 1977. Validation of regression models: methods and examples. Technometrics 19:415-428.

Tausch, R. 1980. Allometric analysis of plant growth in woodland communities. Ph.D. Diss. Utah State Univ., Logan.

Tritton, L.M., and J.W. Hornbeck. 1982. Biomass equations for major tree species of the northeast. USDA Forest. Serv. Gen. Tech. Rep. NE-69.

\section{Some Titles Available from SRM}

\section{JRM Handbook \& Style Manual}

(Revised). Contains directions for authors and typists of manuscripts for the Journal of Range Management. $\$ 1.50$

JRM Index to Volumes 1-35, 1948-1982. Edited by E.H. Reid. Articles are indexed in an authorkeyword-taxon list and also chronologically. 97 pages. $\$ 10.00$

Plants That Poison. By Ervin M. Schmutz and Lucretia Breazeale Hamilton. This handbook belongs in all households in the southwestern United States with children or adults interested in experimenting with "wilderness" foods. Poisonous plants include some popular ornamentals and common food plants such as tomatoes, as well as poisonous native plants. Each entry includes a large, detailed drawing; a description of the plant and its toxic parts; identification of the toxic element involved and symptoms of poisoning. Additional comments are supplied in most instances. 241 pages. $\$ 9.95$

These publications can be ordered from the Society for Range Management, 1839 York St., Denver, CO 80206. Telephone: (303) 355-7070. Prices include postage. A list of additional publications is available.

\section{Proceedings}

Grazing Management Systems for Southwest Rangelands Symposium (April 1980). Edited by Kirk C. McDaniel and Chris Allison and organized by the Range Improvement Task Force, New Mexico State University. The 15 papers included discuss such topics as the history of grazing and grazing systems; plant and animal needs in grazing systems; impacts of grazing systems on range vegetation, livestock, wildlife, and watershed; and evaluating the economic effect of the grazing system. 183 pages. $\$ 5.00$

Brush Management Symposium (February 1983). Edited by Kirk C. McDaniel and sponsored by the Society for Range Management. Origin and history of brush control; points to be considered in brush control; control with herbicides, mechanical means, and fire; impacts on wildlife and watershed; and integrated brush management are discussed in 10 papers. 104 pages. $\$ 10.00$

Rainfall Simulator Workshop (January 1985). Edited by Leonard J. Lane and sponsored by USDA, USDOE, and SRM. Authors of the 9 papers treat problems of research involving runoff and erosion on arid and semiarid lands. Research at Los Alamos, the Nevada Test Site, and the Mojave Desert, among others, is discussed. Extensive appendices of data from rainfall simulation on rangeland erosion plots are included. 68 pages. $\$ 5.00$

International Rangeland Development Sym posium: Institutions for Rangeland Development-Strategies and Lessons Learned (February 1987). These proceedings, edited by James T. O'Rourke, present information from a symposium developed by the International Affairs Committee, SRM, for the Society's Annual Meeting, Boise, Idaho. Some areas discussed are West African Sahel, Mali, Inner Mongolia, Morocco, Kenya, Patagonia, Bhutan, and Lesotho. Sixteen papers, 85 pages. $\$ 15.00$ 